\title{
Ovarian Dermoid Cyst with Secondary Melanocytic Lesion
}

National Cancer Institute

\section{Source}

National Cancer Institute. Ovarian Dermoid Cyst with Secondary Melanocytic Lesion. NCI Thesaurus. Code C40000.

A secondary melanoma or melanocytic nevus that has developed in an ovarian dermoid cyst. 